\title{
Clinical manifestations and associated disorders in children with celiac disease in southern Iran
}

\author{
Mahshid Dehbozorgi ${ }^{1}$, Naser Honar ${ }^{2}$, Maryam Ekramzadeh ${ }^{1}$ and Forough Saki ${ }^{3 *}$
}

\begin{abstract}
Background: Celiac disease (CD) is an immune mediated inflammatory enteropathy, triggered by gluten exposure in HLA-DQ2 and/or -DQ8 genetics. The presentation of celiac disease in children is changing, with increase in nonclassical symptoms. We aim to evaluate the clinical presentations of celiac disease amongst children, diagnosed with CD.

Methods: In this cross sectional study, we investigated the clinical features of 130 celiac patients at hospitals affiliated with Shiraz University of Medical Sciences. We used their hospital charts and conducted an interview with patients and their parents to find out demographic data, symptoms, laboratory, and histopathology findings for Marsh grading.

Results: Celiac disease was detected more amongst females (63.8\%). We found that 5.4\% of the patients had BMI more than 95th percentile. The most common Gl symptoms were abdominal pain, flatulence and constipation. Also, the most common extra intestinal manifestation included bone pain, long term fatigue and anemia. Flatulence, chronic diarrhea, and paresthesia were observed more amongst male participants. The most common comorbidities were type 1 diabetes mellitus and hypothyroidism.

Conclusion: The most common gastrointestinal symptoms amongst our patients were abdominal pain, flatulence and constipation. Furthermore, the most common extra intestinal manifestations included bone pain, long term fatigue and anemia. The most associated comorbidities with CD in our children were type 1 diabetes mellitus and hypothyroidism.
\end{abstract}

Keywords: Celiac disease, Prevalence of clinical manifestation, Southern Iran, T1DM Type 1 Diabetes Melitus

\section{What is known}

- Celiac disease (CD) is an immune-mediated disorder, developed by ingesting gluten in HLA-DQ2 and/or -DQ8 genetics.

- Clinical manifestations of celiac disease vary
* Correspondence: Sakeif@sums.ac.ir

${ }^{3}$ Shiraz Endocrinology and Metabolism Research Center, Shiraz University of Medical Sciences, P.O. Box: 71345-1744, Shiraz, Iran

Full list of author information is available at the end of the article

\section{What is new}

- The most common GI symptoms in our children with $\mathrm{CD}$, were abdominal pain, flatulence and constipation, and the most common extra intestinal manifestation were bone pain, long term fatigue and anemia.

- The most common associated comorbidities with $\mathrm{CD}$ were type 1 diabetes mellitus and hypothyroidism.

C C The Author(s). 2020 Open Access This article is licensed under a Creative Commons Attribution 4.0 International License, which permits use, sharing, adaptation, distribution and reproduction in any medium or format, as long as you give appropriate credit to the original author(s) and the source, provide a link to the Creative Commons licence, and indicate if changes were made. The images or other third party material in this article are included in the article's Creative Commons licence, unless indicated otherwise in a credit line to the material. If material is not included in the article's Creative Commons licence and your intended use is not permitted by statutory regulation or exceeds the permitted use, you will need to obtain permission directly from the copyright holder. To view a copy of this licence, visit http://creativecommons.org/licenses/by/4.0/. The Creative Commons Public Domain Dedication waiver (http://creativecommons.org/publicdomain/zero/1.0/) applies to the data made available in this article, unless otherwise stated in a credit line to the data. 


\section{Background}

Celiac disease (CD) is an immune-mediated disorder, triggered by ingestion of gluten in people who are genetically susceptible [1]. Celiac is a common disease, its prevalence in European countries (Finland, Italy, Germany and UK) was reported to be approximately $1 \%$ [2]. A study in Iran showed that the prevalence of celiac disease amongst Iranian school children was $0.6 \%$ [3]. However, most patients remain undiagnosed due to iceberg pattern of celiac clinical symptoms and its various clinical presentations [4]. This means that many patients have silent celiac disease [5]. Its clinical manifestations are gastrointestinal (GI) and non-gastrointestinal symptoms. GI symptoms are presented in typical celiac disease, which are chronic diarrhea, failure to thrive, vomiting, constipation, abdominal distension, and anorexia. Nongastrointestinal symptoms are seen more in atypical $\mathrm{CD}$ patients and older patients. The symptoms include anemia, osteoporosis, muscle wasting, headache, and epilepsy. Also, CD is associated with some autoimmune diseases, such as Type 1 diabetes, autoimmune thyroiditis, and autoimmune hepatitis [6]. A study on the subject of celiac disease amongst a pediatric population showed that extra-intestinal symptoms are even more common than the classical manifestations [1]. Celiac disease is a relatively common cause of chronic diarrhea in Iran, a Middle Eastern country, and is diagnosed in $2-8 \%$ of patients with type1 diabetes in Iran, Israel and Saudi Arabia. Many of these countries have a per capita wheat consumption, ranking amongst the highest in the world [7]. Plant foods are the major constituent of the Iranian diet, and Iranians rank as one of the top wheatconsuming people in the world with per capita consumption of up to $160 \mathrm{~kg} /$ year. The most significant characteristic of the Iranian diet is the dependency on bread and rice as major energy sources. The percentage of carbohydrate and fat to total energy contribution in the Iranian diet was estimated at 66 and $22 \%$, respectively [8]. Therefore, the gluten-free diet (GFD) presents a real challenge to both patients and clinicians in this region. This is particularly difficult in the absence of any supply of gluten free diet in Middle Eastern countries.

Due to the wide spectrum of clinical manifestation of $\mathrm{CD}$ and its association with other autoimmune disorders in one hand, and lack of sufficient data regarding the clinical spectrum of CD in southern Iran; hence, we initiated this study. Understanding the various clinical presentations of $C D$ in our region helps us to make proper diagnosis of those patients with atypical symptoms during early stages, which can help to prevent the risk of long term complications.

\section{Methods}

A cross sectional study was conducted on 130 children under the age of 18 with celiac disease in southern Iran, from May 2018 till August 2019. CD was diagnosed according to the American College of Gastroenterology (ACG) clinical guideline [9], and was confirmed by positive serological test e.g. anti-tissue transglutaminase (TTG) and also by performing upper endoscopy and having positive pathological results. These patients were under treatment in pediatric gastroenterologists in celiac clinics affiliated with Shiraz University of Medical Sciences (SUMS). We used their hospital charts and conducted an interview patients and their parents to find out demographic data, symptoms, laboratory, and histopathology findings for Marsh grading. This study was approved by the Vice-chancellor of researches and the local Ethics Committee of SUMS. After explaining the study objectives, written informed consent was obtained from children's parents or their guardians.

Inclusion criteria were being diagnosed with celiac disease and age under 18 years. Patients with other chronic diseases, such as chronic renal failure, other gastrointestinal problems and congenital disease were excluded. A subjective data gathering questionnaire was filed by the patients or their parents to evaluate the clinical symptoms. Also, clinical signs, biochemical studies, and results from the upper GI endoscopy were collected from the patients' records.

Tissue transglutaminase: If TTG IgA titer was $>18$ $\mathrm{u} / \mathrm{ml}$, it was considered to be positive. The IgA level were checked in all children. If a child had IgA deficiency, but normal anti TTG IgA level, anti TTG IgG was checked [10].

Upper GI endoscopy: To confirm celiac disease, upper gastrointestinal endoscopy and tissue biopsy from duodenum was performed. This is the gold standard to diagnose CD. All biopsy specimens were graded according to the modified Marsh classification [11].

\section{Statistics}

Collected data were analyzed with the Statistical Package for Social Sciences (SPSS), version 21. Normality of data were checked by Kolmogrov-Smirnov test. In normal distributed data, we used Chi-square and independent ttest to compare the qualitative and quantitative data, respectively. In others, Man-Whitney test was used to compare quantitative data. Data are presented as mean \pm SD. $P$ value $<0.05$ was considered to be statistically significant.

\section{Results}

Of the130 children who were enrolled in this study $83(63.8 \%)$ were female. The mean age of patients was 9.9 \pm 3.2 years (range: $2.5-18$ years), Table 1 . Weight, height 
Table 1 Demographic and anthropometric data of patients with celiac disease and its comparison in both genders

\begin{tabular}{lllll}
\hline Data & Total & Male & Female & $\boldsymbol{P}$-value \\
\hline Age & $9.9 \pm 3.2$ & $10.1 \pm 3.04$ & $9.8 \pm 3.3$ & 0.525 \\
Weight & $29.5 \pm 13.5$ & $28.6 \pm 10.6$ & $30.05 \pm 14.9$ & 0.577 \\
Height & $132.7 \pm 18.2$ & $132.9 \pm 16.9$ & $132.5 \pm 19$ & 0.905 \\
BMl & $16 \pm 3.48$ & $15.7 \pm 2.2$ & $16.1 \pm 4.01$ & 0.518 \\
Anti TTG Ab & $148.1 \pm 166.2$ & $131.8 \pm 185.9$ & $155.2 \pm 155.3$ & 0.444 \\
Weight percentile & $23.02 \pm 25.05$ & $21.1 \pm 25.9$ & $24.1 \pm 24.5$ & 0.514 \\
Height percentile & $27.6 \pm 25.1$ & $25.8 \pm 28.09$ & $28.6 \pm 23.3$ & 0.541 \\
BMl percentile & $26.9 \pm 26.6$ & $23.9 \pm 24.2$ & $28.7 \pm 27.9$ & 0.326 \\
\hline
\end{tabular}

and BMI percentile of the patients were $23.02 \pm 25,27.6$ \pm 25 , and $26.9 \pm 26.6$, respectively. With respect to the aforementioned percentiles, there were no significant differences between males and females, Table 1 . Ten patients $(7.7 \%)$ had family history of $\mathrm{CD}$. The most common GI symptom was abdominal pain (66.2\%). Table 2 shows other common GI manifestations as follows: flatulence, chronic constipation, malodor stool, diarrhea, lactose intolerance, gastro esophageal reflux, and vomiting. Also, Table 2 shows the most frequent presentations among the extra intestinal manifestations were as follows: bone pain (53.8\%), long term fatigue (49.2\%), anemia (41.5\%), anxiety disorder, itchy skin rash, headache, hair loss, repeated oral ulcer, paresthesia, and seizure. From all the manifestations, flatulence $(p$ value $=$

Table 2 Clinical data of patients with celiac disease and its comparison in both genders

\begin{tabular}{lllll}
\hline Clinical manifestation & Total & Male & Female & $\boldsymbol{p}$-value \\
\hline Anemia & $54(41.5 \%)$ & $19(40.4 \%)$ & $35(42.2 \%)$ & 0.846 \\
Long term fatigue & $64(49.2 \%)$ & $23(48.9 \%)$ & $41(49.4 \%)$ & 0.41 \\
headache & $25(19.2 \%)$ & $9(19.1 \%)$ & $16(19.3 \%)$ & 0.986 \\
seizure & $2(1.5 \%)$ & 0 & $2(2.4 \%)$ & 0.284 \\
Chronic abdominal pain & $86(66.2 \%)$ & $32(68.1 \%)$ & $54(65.1 \%)$ & 0.726 \\
Chronic constipation & $54(41.5 \%)$ & $17(36.2 \%)$ & $37(44.6 \%)$ & 0.35 \\
flatulence & $61(46.9 \%)$ & $29(61.7 \%)$ & $32(38.6 \%)$ & 0.011 \\
Chronic diarrhea & $24(18.5 \%)$ & $15(31.9 \%)$ & $9(10.8 \%)$ & 0.003 \\
Gastrointestinal reflux & $15(11.5 \%)$ & $7(14.9 \%)$ & $8(9.6 \%)$ & 0.368 \\
Malodor stool & $42(32.3 \%)$ & $17(36.2 \%)$ & $25(30.1 \%)$ & 0.479 \\
vomiting & $10(7.7 \%)$ & $4(8.5 \%)$ & $6(7.2 \%)$ & 0.792 \\
Lactose intolerance & $18(13.8 \%)$ & $9(19.1 \%)$ & $9(10.8 \%)$ & 0.188 \\
Bone pain & $70(53.8 \%)$ & $24(51.1 \%)$ & $46(55.4 \%)$ & 0.632 \\
paresthesia & $14(10.8 \%)$ & $10(21.3 \%)$ & $4(4.8 \%)$ & 0.004 \\
Itchy skin rash & $29(22.3 \%)$ & $7(14.9 \%)$ & $22(26.5 \%)$ & 0.127 \\
Hair loss & $20(15.4 \%)$ & $4(8.5 \%)$ & $16(19.3 \%)$ & 0.102 \\
Recurrent oral ulcer & $17(13.1 \%)$ & $7(14.9 \%)$ & $10(12 \%)$ & 0.644 \\
Anxiety disorders & $43(33.1 \%)$ & $17(36.2 \%)$ & $26(31.3 \%)$ & 0.573 \\
\hline
\end{tabular}

$0.011)$, chronic diarrhea $(P=0.003)$, paresthesia in hands and feet $(P=0.004)$ were more prevalent amongst male patients, Table 2.

The most common associated comorbidities with $\mathrm{CD}$ were diabetes mellitus type 1(15.4\%), hypothyroidism (7.7\%), down syndrome (1.5\%), attention deficit hyperactivity disorder (ADHD) (1.5\%) and nephrolithiasis $(0.8 \%)$. In total, $3.1 \%$ of the patients had elevated liver enzyme, which was more common amongst male patients $(P=0.007)$, Table 3 .

Body Characteristics: upon evaluating celiac disease on children growth rate, $30.8 \%$ had weight percentile $\leq 3$ and $4.6 \%$ had more than 95th percentile. Also, 21.5\% had height percentile $\leq 5$ and $3.8 \%$ had more than 95th percentile. Out of the total, $29.2 \%$ had BMI less than 5th percentile and $5.4 \%$ had BMI more than 95th percentile. Weight percentile and BMI was not different amongst both genders, but males were significantly shorter than females $(P=0.038)$. Table 4 shows the details.

In this study, histopathology evaluation of patients showed that 4.8\% have Marsh 2, 33.3\% Marsh 3a, 32.4\% Marsh 3b and 29.5\% have Marsh 3c. There was no association between gender and Marsh staging ( $p$ value: 0.241). There was no association between Marsh staging and weight, height, or BMI percentile.

After evaluating the association between clinical manifestations of $\mathrm{CD}$ and Marsh staging, marsh was only associated with long term fatigue ( $p$ value: 0.011 ). In addition to Anti TTG Ab titer had no association with clinical manifestations, and was merely associated with weight percentile in female gender $(p=0.043)$. Although the mean Anti TTG Ab titer in Marsh 2 was $113.5 \pm$ 68.5 and in Marsh 3 was $155.8 \pm 180$, the difference was not statistically significant $(\mathrm{p}=0.604)$. In patients with Marsh 2, the mean weight percentile was $11.8 \pm 4$, and in Marsh 3a, 3b, 3c, weight percentile was $24 \pm 25.4$, but statistically there was no association between Marsh staging and weight percentile $(\mathrm{p}=0.288)$.

In patients with Marsh 2, BMI percentile was 14.4 \pm 14.7, and in Marsh 3a, 3b, 3c it was $28 \pm 26.5$, but similarly, there was no association between Marsh and BMI percentile $(p=0.259)$, which was probably due to few number of children with Marsh 2 stage.

Table 3 Associated disorders with celiac disease in studied patients

\begin{tabular}{lllll}
\hline Associated disease & Total & Male & Female & $\boldsymbol{P}$-value \\
\hline Type 1 Diabetes mellitus & $20(15.4 \%)$ & $8(17 \%)$ & $12(14.5 \%)$ & 0.697 \\
Hypothyroidism & $10(7.7 \%)$ & $5(10.6 \%)$ & $5(6 \%)$ & 0.343 \\
Down syndrome & $2(1.5 \%)$ & $2(4.3 \%)$ & 0 & 0.058 \\
Elevated liver enzyme & $4(3.1 \%)$ & $4(8.5 \%)$ & 0 & 0.007 \\
Nephrolithiasis & $1(0.8 \%)$ & $1(2.1 \%)$ & 0 & 0.182 \\
ADHD & $2(1.5 \%)$ & $2(4.3 \%)$ & 0 & 0.056 \\
\hline
\end{tabular}


Table 4 Body characteristics of children with celiac disease and their comparison in both gender

\begin{tabular}{|c|c|c|c|c|c|c|c|c|c|}
\hline \multirow[t]{2}{*}{ Variables } & \multicolumn{3}{|c|}{ Weight percentile } & \multicolumn{3}{|c|}{ Height percentile } & \multicolumn{3}{|c|}{ BMI percentile } \\
\hline & Female & Male & Total & Female & male & Total & Female & Male & Total \\
\hline$\leq 5 \%$ & $25.3 \%$ & $40.4 \%$ & $30.8 \%$ & $15.7 \%$ & $31.9 \%$ & $21.5 \%$ & $28.9 \%$ & $29.8 \%$ & $29.2 \%$ \\
\hline $5-95 \%$ & $71.1 \%$ & $53.2 \%$ & $64.6 \%$ & $81.9 \%$ & $61.7 \%$ & $74.6 \%$ & $65.1 \%$ & $66 \%$ & $65.4 \%$ \\
\hline$\geq 95 \%$ & $3.6 \%$ & $6.4 \%$ & $4.6 \%$ & $2.4 \%$ & $6.4 \%$ & $3.8 \%$ & $6 \%$ & $4.3 \%$ & $5.4 \%$ \\
\hline$P$ value & & 0.121 & & & $0.038 *$ & & & 0.911 & \\
\hline
\end{tabular}

* Significant $\mathrm{P}$ value showed the comparison of related percentiles in both sex

Height percentile in patients with Marsh 3c was 20.96 \pm 16.8, and in Marsh 2, 3a, 3b was $30.9 \pm 26.6$; hence, height in Marsh 3c was shorter in comparison with other children $(\mathrm{p}=0.009)$. Figure 1 shows the details.

\section{Discussion}

This retrospective study provides data on clinical manifestation of Celiac disease amongst children in southern Iran. It showed that the most common GI symptoms were abdominal pain, flatulence and constipation, and the most common extra intestinal manifestation were bone pain, long term fatigue and anemia. The most associated comorbidities with CD are type 1 diabetes mellitus and hypothyroidism. From all the manifestations, flatulence, chronic diarrhea, paresthesia in hands and feet were observed more amongst male patients. One study evaluating the gender effect on manifestation of CD in New York showed that men had lower bone density at radius and lower total cholesterol and had indirect evidence for more malabsorptive disorders [12]. We could not find any related article in Iran, showing any association between clinical manifestation of celiac disease and gender. In one study on GI and non-GI presentation in patients with $\mathrm{CD}$ in Italy, Romania and Iran found no correlation between clinical
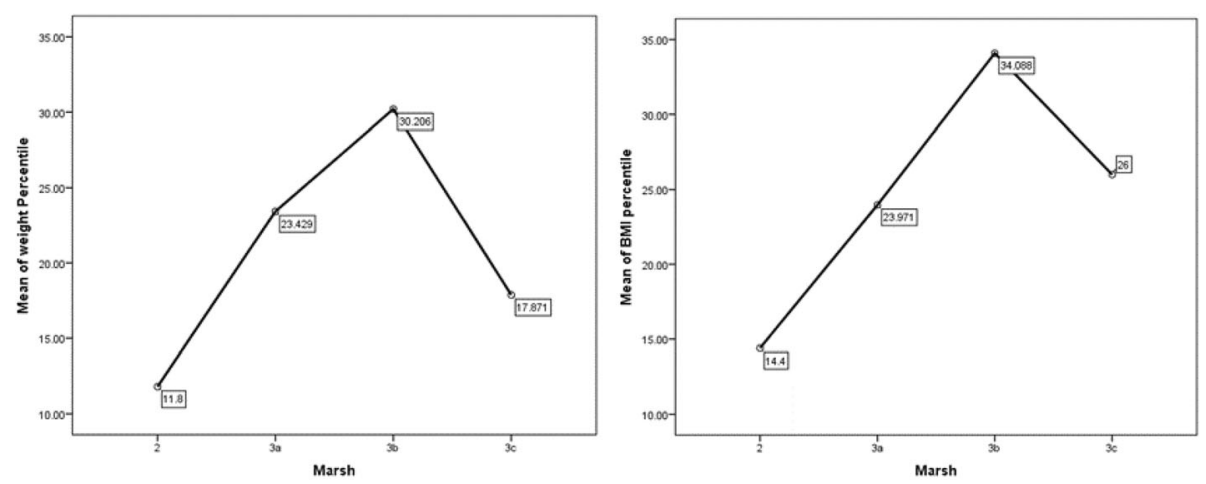

a

c
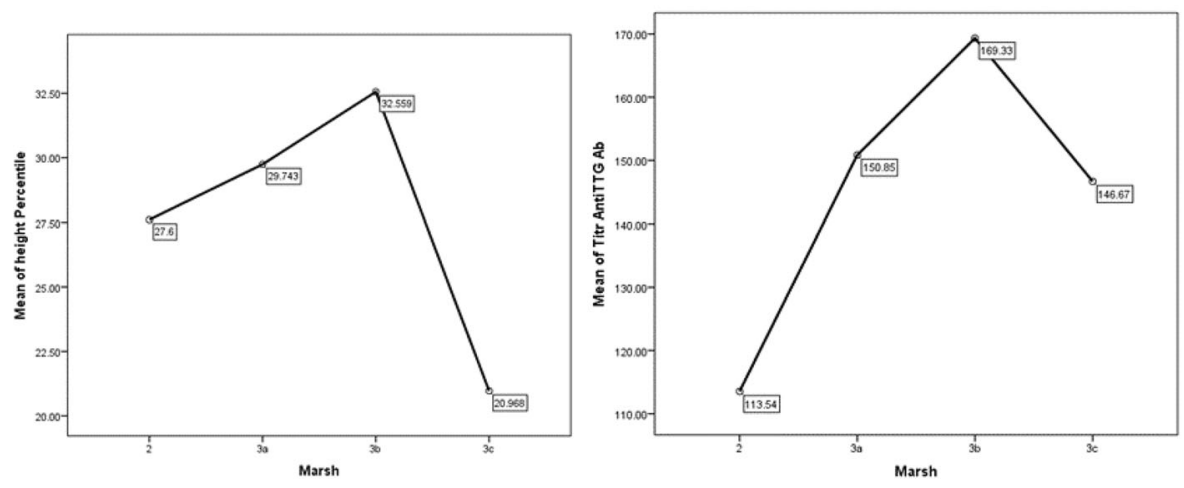

b

d

Fig. 1 Anthropometric indices include weight(a), height(b), and BMl percentile(c) and anti $\Pi G$ antibody $(\mathbf{d})$ in different Marsh stages of children with celiac disease 
manifestation and gender, but in the mentioned countries there were more female patients [13].

In the present study, it was found that celiac disease was detected more amongst females (36.2\% male vs. $63.8 \%$ female). In a similar pattern, clinical manifestation of $\mathrm{CD}$ and gender and age related features showed that the prevalence of celiac disease among females is four times more than males [14]. A female predominance might have some clinical implications; however, if a patient is suspected of $\mathrm{CD}$, whether male or female, laboratory testing is recommended [7]. However, the pathophysiology underlying the higher rate of $C D$ amongst female remains unclear, but the present findings support the hypotheses that gender biology plays a role in the disease development. Genetic factors, such as permissive HLA, gene variants on the X chromosome, and a higher prevalence in female relatives of the $\mathrm{CD}$ patients support our hypothesis [15-17].

Failure to thrive (FTT) is a typical manifestation of Celiac disease in pediatrics; however, a recent study in Wisconsin Hospital showed that $5 \%$ of children affected by celiac disease had BMI more than 95th percentile [18]. In the present study, $5.4 \%$ of the patients had BMI more than 95th percentile. Recently, being overweight and obesity has become more common amongst children with CD [19]. One possible mechanism might be the unpalatability of gluten-free foods which causes a preference for high caloric fat and protein foods [15]. Also, the increased prevalence of overweightness in children with CD can be explained by the global trend [20]. Semeraro et al. proposed an interesting hypothesis about the development of over-nutrition status in $\mathrm{CD}$ children which was the compensatory high energetic yield secondary to slow functional adaptation of the atrophic mucosa in these patients [21]. It was revealed that some children with celiac disease suffered from obesity and should be considered for long term treatments and follow ups.

A study in India showed that diarrhea, FTT, and distension are the most common symptoms in patients with CD [22]. Amongst Iranian adult patients with celiac disease, diarrhea, bloating, and weight loss were reported as the most common symptoms [13, 23]. However, in children in southeastern Iran, abdominal pain was the most common symptom with a prevalence of $41 \%$ [24]. In the present study, the most common symptom was abdominal pain followed by flatulence and constipation. We found that nonspecific symptoms like abdominal pain, flatulence and constipation might be the only presentations in children with $\mathrm{CD}$, and should be taken into consideration. Recent guidelines recommend screening cases to find high risk population for $\mathrm{CD}$, such as children with family history of $\mathrm{CD}$ like siblings or other first-degree relatives, children with other autoimmune diseases e.g. Type 1 diabetes, autoimmune hepatitis, and autoimmune thyroiditis, and those with chromosomal disorders associated with CD [25].

Reports from India showed that type 1 diabetes mellitus and hypothyroidism were the most common associated autoimmune conditions in children with CD [26]. One study in Australia showed that T1DM was the most common associated condition [27]. However, the present study showed that T1DM and hypothyroidism were the most common associated disease with CD amongst Iranian children. Honar et al. revealed that the prevalence of celiac disease in diabetes mellitus type 1 children in Iran was more common than that of America and Europe, but similar to that of Turkey [8]. Samasca et al. reported that about $30 \%$ of all patients with $\mathrm{CD}$ have one or more autoimmune disease while autoimmune diseases were found amongst 3 to $9.4 \%$ of the general population, but this association has not been completely understood, yet. A higher prevalence of autoimmune diseases amongst the relatives of $\mathrm{CD}$ children suggests that the genetic background is the main factor [28].

One study in Spain found that abnormal liver enzymes was seen in $40 \%$ of patients with CD [29]. In contrast, just $3 \%$ of the children in our study had abnormal liver enzyme, which might be due to increased intestinal permeability and alterations in gut microbiota, chronic intestinal inflammation, and genetic predisposition [30]. In our study, the patients with obesity had normal liver enzymes; consequently, we found that the elevated liver enzyme was not due to obesity and it might have been related to the $\mathrm{CD}$ itself. One study in Iran showed that the prevalence of $\mathrm{CD}$ in patients with nonalcoholic fatty liver disease was higher than the general population [31]. Also, another study showed that $15-55 \%$ of patients with $\mathrm{CD}$ had mild to severe liver complications. Hence, physicians should be aware that celiac disease could present itself with isolated liver enzyme elevation and evaluate liver enzyme in all patients with celiac disease [32]. However, it was shown that severity of clinical presentation, and the time of detection was associated with severity of histological damage [33]. Nowadays, physician's knowledge on the heterogeneous presentation has increased, and also, available noninvasive screening tests of at-risk children make the diagnosis possible in earlier stages. Hence, we detected a lower incidence of elevated liver transaminase.

In this study, we evaluated the association of Marsh staging and clinical manifestations of celiac disease. We found that Marsh just correlated with long term fatigue. Among anthropometric measurements, it was shown that children's height with $C D$ in Marsh 3c was shorter than the other groups. Weir et al. found no significant association between histological findings and the clinical data, including gender, age, symptoms, and associated disorders, which might be due 
to the fact that duodenal involvement by $\mathrm{CD}$ in children is frequently patchy, more so than what is seen in adult patients with CD [34].

Despite many strengths, we had few limitations. It would have been much better if this study was conducted as a prospective trial, because we could have followed the effect of gluten free diet on clinical manifestations, and histologic findings of children with celiac disease in Iran. Also, it would be better if we had evaluated the patients' compliance in using GFD.

\section{Conclusion}

The present study showed that the most common GI symptoms in the children with $\mathrm{CD}$, are abdominal pain, flatulence and constipation, and the most common extra intestinal manifestation are bone pain, long term fatigue and anemia. The most common associated comorbidities with $\mathrm{CD}$ are type 1 diabetes mellitus and hypothyroidism. From all the manifestations, flatulence, chronic diarrhea, paresthesia in hands and feet were observed more amongst male patients. Conducting a prospective study is recommended to evaluate the effect of gluten free diet on clinical manifestations, and histologic findings of children with celiac disease in Iran.

\section{Abbreviations}

CD: Celiac disease; Gl: Gastrointestinal; ACG: American College of Gastroenterology; TTG: Anti-tissue transglutaminase; SUMS: Shiraz University of Medical Sciences; BMI: Body mass index; T1DM: Type 1 diabetes

\section{Acknowledgements}

The authors wish to thank Mr. H. Argasi at the Research Consultation Center (RCC) of Shiraz University of Medical Sciences for his invaluable assistance in editing this manuscript.

\section{Authors' contributions}

All authors have read and approved the manuscript. MD, design, data gathering, preparing the manuscript, $\mathrm{NH}$ : design, data gathering, preparing the manuscript, ME, data gathering, preparing the manuscript, FS: concept, design, data gathering, data analysis, preparing the manuscript and the correspondence

\section{Funding}

There is no financial support.

\section{Availability of data and materials}

The datasets used and/or analyzed during the current study are available from the corresponding author upon request.

\section{Ethics approval and consent to participate}

Shiraz University of Medical Sciences local Ethic Committee and Vicechancellor of research at SUMS approved this study with number 15563. All patients signed a written informed consent form after explaining the aim, method and goal of the study for participation.

\section{Consent for publication}

Not Applicable.

\section{Competing interests}

Naser Honar, Forough Saki, Mahshid Dehbozorgi, Maryam Ekramzadeh declare that they have no conflict of interest.

\section{Author details}

${ }^{1}$ Shiraz University of Medical Sciences, Shiraz, Iran. ${ }^{2}$ Neonatal Research Center, Shiraz University of Medical Sciences, Shiraz, Iran. ${ }^{3}$ Shiraz Endocrinology and Metabolism Research Center, Shiraz University of Medical Sciences, P.O. Box: 71345-1744, Shiraz, Iran

Received: 22 February 2020 Accepted: 20 May 2020

Published online: 27 May 2020

\section{References}

1. Fasano A. Clinical presentation of celiac disease in the pediatric population. Gastroenterology. 2005;128(4):S68-73.

2. Mustalahti K, Catassi C, Reunanen A, Fabiani E, Heier M, McMillan S, et al. The prevalence of celiac disease in Europe: results of a centralized, international mass screening project. Ann Med. 2010;42(8):587-95.

3. Dehghani SM, Haghighat M, Mobayen A, Rezaianzadeh A, Geramizadeh B. Prevalence of celiac disease in healthy Iranian school children. Ann Saudi Med. 2013;33(2):159-61.

4. Cronin CC, Shanahan F. Exploring the iceberg-the spectrum of celiac disease. Nature Publishing Group; 2003.

5. Charidimou A, Loizou S, Triantafyllou K. The celiac iceberg what textbooks do not clarify (and beyond). Arch Hellenic Med. 2010;27(6):891-6.

6. Lionetti E, Catassi C. New clues in celiac disease epidemiology, pathogenesis, clinical manifestations, and treatment. Int Rev Immunol. 2011; 30(4):219-31.

7. Cummins AG, Roberts-Thomson IC. Prevalence of celiac disease in the AsiaPacific region. J Gastroenterol Hepatol. 2009;24(8):1347-51.

8. Posner BM, Quatromoni PA, Franz M. Nutrition policies and interventions for chronic disease risk reduction in international settings: the INTERHEALTH nutrition initiative. Nutr Rev. 1994;52(5):179-87.

9. Rubio-Tapia A, Hill ID, Kelly CP, Calderwood AH, Murray JA. ACG clinical guidelines: diagnosis and management of celiac disease. Am J Gastroenterol. 2013;108(5):65.

10. Honar N, Karamizadeh Z, Saki F. Prevalence of celiac disease in patients with type 1 diabetes mellitus in the south of Iran. Turkish J Gastroenterol. 2013; 24(2):122-6.

11. Marsh MN, Johnson MW, Rostami K. Mucosal histopathology in celiac disease: a rebuttal of Oberhuber's sub-division of Marsh III. Gastroenterol Hepatol Bed Bench. 2015;8(2):99.

12. Bai D, Brar P, Holleran S, Ramakrishnan R, Green PH. Effect of gender on the manifestations of celiac disease: evidence for greater malabsorption in men. Scand J Gastroenterol. 2005:40(2):183-7.

13. Ehsani-Ardakani MJ, Villanacci V, Volta U, Manenti S, Caio G, Giovenali P, et al. Gastrointestinal and non-gastrointestinal presentation in patients with celiac disease. Arch Iran Med. 2013;16(2):78.

14. Llorente-Alonso M, Fernandez-Acenero M, Sebastian M. Gluten intolerance: sex-and age-related features. Can J Gastroenterol Hepatol. 2006;20(11):719-22.

15. Megiorni F, Mora B, Bonamico M, Barbato M, Montuori M, Viola F, et al. HLA-DQ and susceptibility to celiac disease: evidence for gender differences and parent-of-origin effects. Am J Gastroenterol. 2008;103(4):997.

16. Trynka G, Hunt KA, Bockett NA, Romanos J, Mistry V, Szperl A, et al. Dense genotyping identifies and localizes multiple common and rare variant association signals in celiac disease. Nat Genet. 2011;43(12):1193.

17. Singh P, Arora S, Lal S, Strand TA, Makharia GK. Risk of celiac disease in the first-and second-degree relatives of patients with celiac disease: a systematic review and meta-analysis. Am J Gastroenterol. 2015;110(11):1539.

18. Telega G, Bennet TR, Werlin S. Emerging new clinical patterns in the presentation of celiac disease. Arch Pediatr Adolesc Med. 2008;162(2):164-8.

19. Diamanti A, Capriati T, Basso MS, Panetta F, Di Ciommo Laurora VM, Bellucci $F$, et al. Celiac disease and overweight in children: an update. Nutrients. 2014;6(1):207-20.

20. De Onis M, Blössner M, Borghi E. Global prevalence and trends of overweight and obesity among preschool children. Am J Clin Nutr. 2010;92.

21. Semeraro LA, Barwick KW, Gryboski JD. Obesity in celiac sprue. J Clin Gastroenterol. 1986;8(2):177-80.

22. Poddar U, Thapa BR, Singh K. Clinical features of celiac disease in Indian children: are they different from the west? J Pediatr Gastroenterol Nutr. 2006:43(3):313-7.

23. Masjedizadeh R, Hajiani E, Hashemi J, Shayesteh AA, Moula K, Rajabi T. Celiac disease in south-west of Iran. World J Gastroenterol: WJG. 2006;12(27): 4416 
24. Shahraki T, Hill ID. Clinical spectrum of celiac disease in children in Sistan and Shahraki Baluchestan Province. Arch Iran Med. 2016;19(11):762.

25. Lenhardt A, Plebani A, Marchetti F, Gerarduzzi T, Not T, Meini A, et al. Role of human-tissue transglutaminase lgG and anti-gliadin lgG antibodies in the diagnosis of coeliac disease in patients with selective immunoglobulin a deficiency. Dig Liver Dis. 2004;36(11):730-4.

26. Nijhawan S, Katiyar P, Nagaich N, Saradava V, Nijhawan M, Gupta G, Mathur A, Sharma R, Nepalia S. Prevalence of associated disorders inIndian patients with celiac disease. Indian J Gastroenterol. 2013;32(5):330-4.

27. Lauret E, Rodrigo L. Celiac disease and autoimmune-associated conditions. Biomed Res Int 2013;2013.

28. Samasca G, Sur G, Lupan I, Tilinca M, Deleanu D. Celiac disease as an autoimmune condition. Central-Eur J Immunol. 2014;39(3):396.

29. Farre C, Esteve M, Curcoy A, Cabre E, Arranz E, Amat L, et al. Hypertransaminasemia in pediatric celiac disease patients and its prevalence as a diagnostic clue. Am J Gastroenterol. 2002;97(12):3176.

30. Anania C, De Luca E, De Castro G, Chiesa C, Pacifico L. Liver involvement in pediatric celiac disease. World I Gastroenterol. 2015;21(19):5813.

31. Rahimi A, Daryani NE, Ghofrani H, Taher M, Pashaei MR, Abdollahzade S, et al. The prevalence of celiac disease among patients with non-alcoholic fatty liver disease in Iran. Turk J Gastroenterol. 2011;22(3):300-4.

32. Zali MR, Nejad MR, Rostami K, Alavian SM. Liver complications in celiac disease. Hepatitis Monthly. 2011;11(5):333.

33. Kivelä L, Kaukinen $\mathrm{K}$, Lähdeaho M-L, Huhtala H, Ashorn M, Ruuska T, et al. Presentation of celiac disease in Finnish children is no longer changing: a 50-year perspective. J Pediatr. 2015;167(5):1109-15 e1.

34. Weir DC, Glickman JN, Roiff T, Valim C, Leichtner AM. Variability of histopathological changes in childhood celiac disease. Am J Gastroenterol. 2010;105(1):2071109-12.

\section{Publisher's Note}

Springer Nature remains neutral with regard to jurisdictional claims in published maps and institutional affiliations.

Ready to submit your research? Choose BMC and benefit from:

- fast, convenient online submission

- thorough peer review by experienced researchers in your field

- rapid publication on acceptance

- support for research data, including large and complex data types

- gold Open Access which fosters wider collaboration and increased citations

- maximum visibility for your research: over $100 \mathrm{M}$ website views per year

At $\mathrm{BMC}$, research is always in progress.

Learn more biomedcentral.com/submissions 